\title{
Vorsicht: irreführende Rechnungen
}

Die Patentämter versenden in aller Regel keine Rechnungen. Die Patentämter gehen davon aus, dass der Schutzrechtsinhaber bzw. der Antragsteller die gesetzlichen Fristen selbsttätig überwacht und bei Fälligkeit die entsprechenden Amtsgebühren bezahlt.

Erhält man daher eine Rechnung eines Patentamts ist Vorsicht geboten. Sehr oft handelt es sich um eine irreführende Rechnung, die einen amtlichen Eindruck erweckt, deren Absender aber kein Amt ist.

Oftmals wird eine sinnlose Eintragung in eine unbekannte Datenbank angeboten. Ein derartiges Angebot ist wirtschaftlich wertlos. Das EUIPO hat eine Datenbank mit typischen Absendern derartiger irreführender Rechnungen erstellt, die unter dem Link ,https:// euipo.europa.eu/ohimportal/de/rcd-misleading-invoices“ “ abgerufen werden können. ${ }^{1}$

\footnotetext{
${ }^{1}$ EUIPO, https://euipo.europa.eu/ohimportal/de/rcd-misleading-invoices, abgerufen am 10. Juli 2021.
} 